\title{
Resources utilisation and economic burden of percutaneous vertebroplasty or percutaneous kyphoplasty for treatment of osteoporotic vertebral compression fractures in China: a retrospective claim database study
}

Dehong Yang ${ }^{1 *}$, Yanlei Zhang ${ }^{2}$, Xiao $\mathrm{Ma}^{2}$, Li Huo ${ }^{2}$, Liran $\mathrm{Li}^{3}$ and Yue Gao ${ }^{3}$

\begin{abstract}
Background: Osteoporotic vertebral compression fractures (OVCF) is a common and often debilitating complication of osteoporosis, leading to significant morbidity and increased mortality. Percutaneous vertebroplasty (PVP) and Percutaneous kyphoplasty (PKP) are recommendable surgical treatments for OVCF.

Objective: To evaluate PVP/PKP utilisation and their related direct medical costs for OVCF treatment in China from the payer perspective.

Methods: A population-based medical claims database of a metropolitan city in China was analysed from the payer perspective, which included all inpatient claims from 01/01/2015 to 31/12/2017. All vertebral fractures patients that met the eligibility criteria (aged $\geq 50$ years old, having vertebral fracture diagnosis, without unrelated diseases diagnoses such as tumour and scoliosis, received PVP/PKP) were deemed as OVCF patients. Baseline characteristics, surgery rate, length of stay in hospital, time to re-surgery, and costs (including costs per hospitalisation and annual costs) were described. Survival analysis function was used to estimate the re-surgery rate.

(Continued on next page)
\end{abstract}

\footnotetext{
* Correspondence: drmyang@yahoo.com

'Department of Spinal Surgery, Nanfang Hospital, Southern Medical

University, AD: No.1838 North Guangzhou Avenue, Guangzhou 510515, PR

China

Full list of author information is available at the end of the article
}

(c) The Author(s). 2020 Open Access This article is licensed under a Creative Commons Attribution 4.0 International License, which permits use, sharing, adaptation, distribution and reproduction in any medium or format, as long as you give appropriate credit to the original author(s) and the source, provide a link to the Creative Commons licence, and indicate if changes were made. The images or other third party material in this article are included in the article's Creative Commons licence, unless indicated otherwise in a credit line to the material. If material is not included in the article's Creative Commons licence and your intended use is not permitted by statutory regulation or exceeds the permitted use, you will need to obtain permission directly from the copyright holder. To view a copy of this licence, visit http://creativecommons.org/licenses/by/4.0/. The Creative Commons Public Domain Dedication waiver (http://creativecommons.org/publicdomain/zero/1.0/) applies to the data made available in this article, unless otherwise stated in a credit line to the data. 


\begin{abstract}
(Continued from previous page)
Results: Of the 50,686 patients with OVCF identified, 14,527 (28.66\%) received a total number of 15,599 records of PVP/ PKP surgeries from 2015 to 2017. Mean age was 75 at the first surgery captured in the database analysis period; females accounted for $79.54 \%$ of all cases. The median length of surgery stay was 9 days. Cumulative re-surgery rates were $1.22 \%$ in 30 days, $2.58 \%$ in 90 days, 3.61\% in 183 days, $5.42 \%$ in 1 year, and $7.95 \%$ in 2 years. There was no significant difference in re-surgery rate between PVP and PKP $(p=0.3897)$. The median time to the re-surgery was 139 days. Mean costs per PVP/PKP-related hospitalisation were 35,906 CNY/5122 USD (34,195 CNY/4878USD for PVP, 44,414 CNY/6336 USD for PKP, $p<0.01$ ). The overall costs of hospitalisation averaged 186.61 million CNY (26.62 million USD) per year in this metropolitan city.

Conclusion: From 2015 to 2017, nearly one-third of OVCF inpatients received PVP/PKP and the re-surgery rate was 7.95\%. PVP/PKP procedures for OVCF place a high economic burden for both the healthcare system and patients. Early detection and treatment of patients with osteoporosis are critical in China.
\end{abstract}

Keywords: OVCF, Percutaneous vertebroplasty, Percutaneous kyphoplasty, Surgery, Costs

\section{Background}

Osteoporosis places significant disease burden on patients, ranking the seventh among common chronic diseases with over 200 million people affected worldwide $[1,2]$. In China, the prevalence of osteoporosis has been rising over the past few decades in parallel with the aging population. The prevalence of osteoporosis in mainland China was approximately $13 \%$ for adults aged 20 and over during the period of 1980-2008 and rose to about $28 \%$ for people aged 15 and over between 2012 and 2015 [3, 4] and the disease disproportionally affects females [4-6]. For most patients, osteoporosis is a silent and insidious disorder and often not diagnosed until fractures have occurred.

Osteoporotic vertebral compression fractures (OVCF) is a common and often debilitating complication of osteoporosis, leading to chronic back pain, insomnia, reduced activity, depression, and increased mortality [1]. Thirty to fifty percent of people over 50 years old could be affected by OVCF worldwide; in Europe, the incidence of OVCF was 570 per 100,000 males and 1070 per 100,000 females; in South Korea, the 5-year incidence of OVCF was 852 per 100,000 persons [7]. In Shanghai, a metropolitan city in China, $14.4 \%$ of people over 65 years old and $20.1 \%$ of people over 80 years old were suffering from OVCF and the risk of OVCF was significantly higher for females compared to their male counterparts (18.5\% vs. $12.4 \%)$ [8]. Many countries around the world have studied the economic burden of OVCF. A report shows that the total annual costs of OVCF in the United States in 2005 exceeded 1 billion USD; the average annual cost of OVCF in Germany between 2006 and 2010 was 6490 EUR (7203 USD/ 50,492 CNY); the direct medical cost of OVCF patients in Canada from 2011 to 2012 was 25,965 CAD (19,993 USD/136,316 CNY) per year; China's one-year direct medical cost for OVCF patients from 2010 to 2012 was 21,474 CNY (3063 USD) [9-12].
The OVCF treatment guidelines include both conservative and surgical interventions [1]. The conservative therapies entail initial bed rest, use of analgesics, external immobilization; while surgical treatments include percutaneous vertebroplasty (PVP) and percutaneous kyphoplasty (PKP). According to China's guidelines, for surgical treatments, PVP is recommended for patients with OVCF who are refractory to treatment with braces and medication, but not suitable for patients with extremely severe vertebral compression fractures that cannot establish working channels and merge with the lesions of the same site requiring surgical treatment, pedicle fractures, severe compression fractures; PKP is recommended for pain or kyphosis caused by osteoporotic compression fracture, but not for stable, cured, painless osteoporotic compression fracture, osteoporotic burst fracture [1].

In addition to the surgical treatment, anti-osteoporosis treatment is an integral part of the clinical management in order to fundamentally improve bone mass and strength, and reduce the risk of re-fracture [1]. In China, the recommended anti-osteoporosis therapy includes calcium and vitamin D supplements, anti-resorptive drugs, bone anabolic drugs, and traditional Chinese medicine [13]. However, in China, a survey showed that about half of osteoporotic patients are not diagnosed even if they had fractures; moreover, less than a quarter of the patients are receiving effective anti-osteoporosis drugs before fractures [14].

Previously, a number of studies have explored the clinical efficacy and costs of PVP/PKP in China based on hospital data. Evidence showed that PVP/PKP can effectively relieve fracture-related pain, and PVP/PKP is considered as the best choice for OVCF [1, 15-17]. Nevertheless, regardless of OVCF intervention modality, $\mathrm{PVP} / \mathrm{PKP}$ surgery is very expensive and can impose a heavy financial burden on patients. From 2012 to 2017, studies estimated that the hospital costs of PVP were 14, 
$328 \mathrm{CNY}$ to $44,916 \mathrm{CNY}$ (about 2044 USD to 6407 USD) per time, while those of PKP were 31,681 CNY to 50,184 CNY (about 4519 USD to 7159 USD) [18-21].

However, no studies so far have examined PVP/PKP utilisation using a large-scale population-based database in China. Therefore, the primary objective of this study is to estimate PVP/PKP utilisation, including surgery rate and re-surgery rates, and related direct costs in China through analysing a citywide inpatient claims database.

\section{Methods}

This study is a retrospective administrative claims database study to estimate the surgery/re-surgery rates and direct medical costs in patients with OVCF and receiving PVP/PKP surgery from the health payer perspective.

\section{Study setting and data source}

Insurance claim data is a commonly used large-scale database for healthcare study. In China, over $95 \%$ of the residents have been covered by basic medical insurance. All data in this study were de-identified and extracted from an anonymous metropolitan inpatient claims database from 01/01/2015 to 31/12/2017. All OVCF patients receiving $\mathrm{PVP} / \mathrm{PKP}$ surgery during such a period would be followed up to their second PVP/PKP surgery or the end of 2017 whichever comes first. The date of first surgery (PVP/PKP) during study time frame would constitute the index date. Detailed information on patients included demographics, diagnosis, treatment, costs, and so on. Patients meeting all eligibility criteria detailed below were included in this study. Because only deidentified records were used in the analysis, ethical approval and informed consent were not required, which was consistent with the local medical research policy on using electronic health data.

\section{Patient selection}

Records with admission date from 01/01/2015 to 31/12/ 2017 were extracted. Inclusion criteria included aged $\geq 50$ years old, recorded OVCF or vertebral fracture as admission diagnosis, and received PVP and/or PKP surgery. Patients diagnosed with unrelated diseases were excluded (tumour, spinal deformity, scoliosis, spondylitis, and disc herniation). Patients receiving PVP/PKP in cancer hospitals were also excluded. In the main analyses, a key assumption was that a vertebral fracture with PVP/ PKP without unrelated diseases was in fact osteoporotic, which was aligned with osteoporosis diagnosis criteria according to Chinese guideline [13]. Keywords used for patient selection was displayed in Appendix A.

\section{Surgery and re-surgery status}

All PVP/PKP surgery records were classified into three categories: PVP, PKP, and unclear. Due to lack of standardized nomination for surgery procedure, surgeries of PVP or PKP that could not be judged by information in the extracted database were marked as "unclear". Surgery status was examined in terms of surgery rate and Length of Stay (LOS) in hospitals. Surgery rate was calculated by dividing the patient number receiving PVP/ PKP by the total number of OVCF patients. Re-surgery status was explored in terms of the cumulative resurgery rate for 3 months, 6 months, 1 year and 2 years follow-up, and median length of the time interval to resurgery. The first surgical record captured in the database during the study period was assumed as the first surgical record of patient and ensuing PVP or PKP procedures were identified as re-surgery.

\section{Direct medical costs}

Direct medical costs of PVP/PKP among OVCF patients were summarized in terms of both cost per hospitalisation (per visit) and annual costs (all PVP/ PKP related costs in 1 year). Costs per hospitalisation were the average of total PVP/PKP surgery-related hospitalisation costs, and could be broken down to different categories, for example, medical fee, diagnosis fee, treatment fee, and so on. The annual costs were the average of the sum of all PVP/PKP surgeryrelated hospitalisation costs.

\section{Statistical methods}

Descriptive analysis was employed to characterize patient profiles at their first inpatient care. Continuous variables were presented as mean, standard deviation, median, inter-quartile range whereas categorical variables were displayed in frequencies and percentages. A re-surgery function was developed to illustrate the probability of re-surgery with the time interval between the first and second surgery. Patients without re-surgery were censored at the end of 2017. Kaplan-Meier method was used to establish the re-surgery function. Based on the function, cumulative re-surgery rates and their 95\% confidence intervals were estimated at different time points, specifically, 3 months, 6 months, 1 year, and 2 years. The calculation of the time interval to re-surgery is shown in the following formula:

\section{Time inteval $=$ admission date of 2 nd visit -discharge date of 1 st visit}

Non-parametric statistical tests were used for the costs, days (Mann-Whitney Test for two groups, and Kruskal-Wallis Test for three or more groups) and resurgery rate (Log-rank Test and Wilcoxon Test) 
comparison, $\alpha=0.05$ was used as the significant level for all comparisons.

All analyses were conducted using Stata SE 14.

\section{Subgroup analyses}

Two subgroup analyses were performed on age and sex groups because they have a significant effect on the incidence of osteoporosis and vertebral fractures. Sex was divided into two categories: male and female; age was divided into five categories: $50-59,60-69,70-79,80-89$, $90+$. LOS, re-surgery rates and costs were counted and compared between subgroups.

\section{Sensitivity analysis}

A key assumption of the main analysis was that all patients who met the eligibility criteria were identified as OVCF patient even if they did not have an OVCF diagnosis. To test the robustness of the results, a sensitivity analysis was performed focusing on patients who had established OVCF diagnosis. All the statistical analyses in the main analysis were implemented in the sensitivity analysis, except for the annual costs.

\section{Results}

Study population

Extracted raw data included 8,524,679 records. A total of 50,686 OVCF patients with 64,855 hospitalisations were identified, among them 14,527 (28.66\%) patients received PVP/PKP with 15,599 records (Fig. 1).

\section{Baseline characteristics}

Of the 50,686 OVCF patients, 15,437 (30.46\%) were male and 35,249 (69.54\%) were female. Among 14,527 patients, $8760(60.30 \%)$ underwent PVP, 3048 (20.98\%) underwent PKP, and 2719 (18.72\%) were unclear for the first surgery. PVP/PKP patients were 75 -year-old on average and females accounted for $79.54 \%$. Most surgeries were performed in general hospitals $(60.69 \%)$ and Chinese traditional medicine hospitals (28.22\%). Tertiary care hospitals accounted for 92.16\%. (Table 1).

\section{Surgery and re-surgery status}

Of all OVCF patients, the total surgery rate was $28.66 \%$, of which PVP was $17.30 \%$ and PKP was $6.03 \%$ (Table 2). Median LOS in the hospital was 9 days, of which PVP was 9 days and PKP was 10 days (Table 3 ).

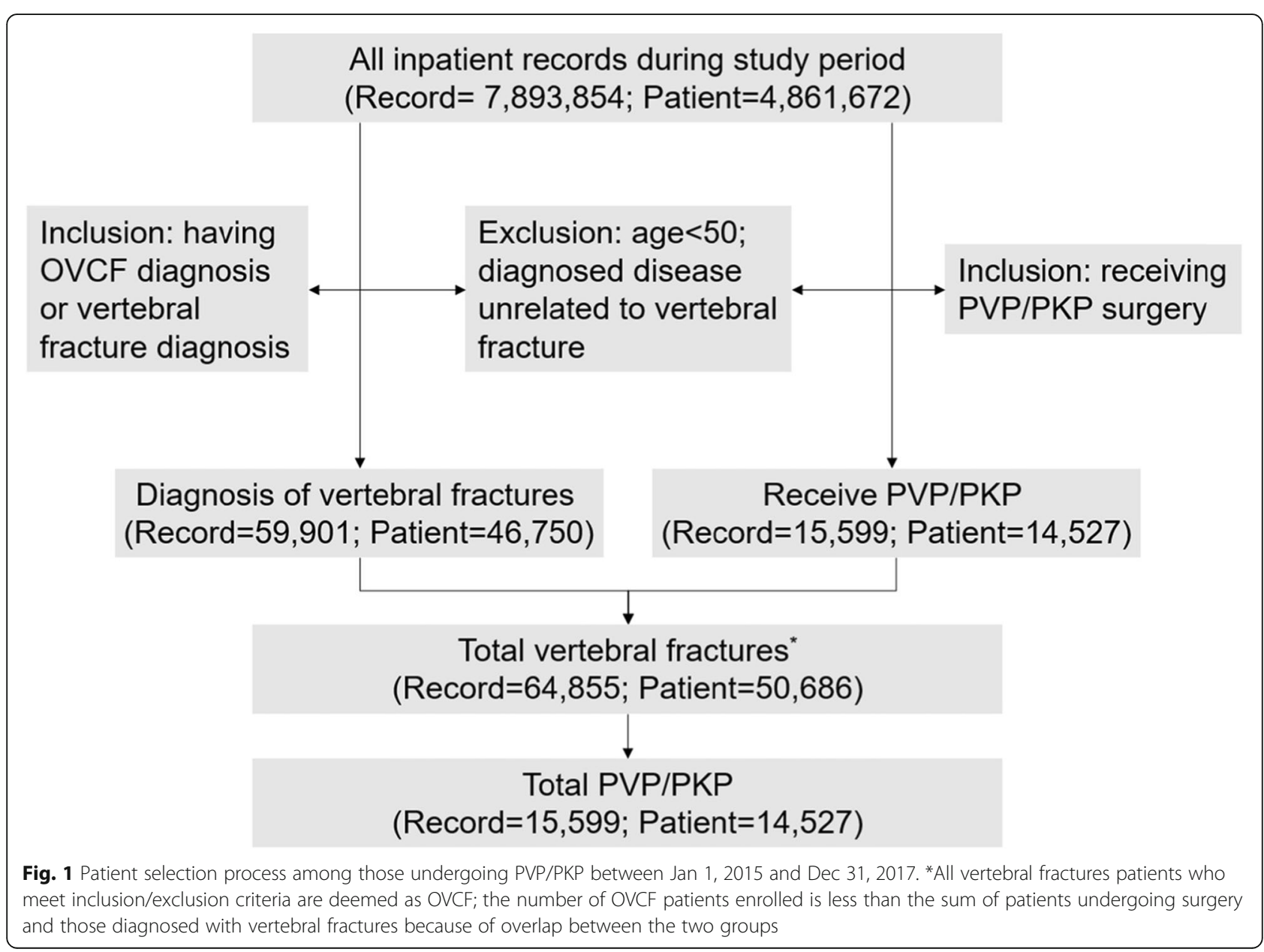


Table 1 Baseline characteristics for PVP/PKP patients

\begin{tabular}{|c|c|c|c|c|c|c|c|c|}
\hline & \multicolumn{2}{|c|}{ Total Population } & \multicolumn{2}{|l|}{ PVP } & \multicolumn{2}{|l|}{ PKP } & \multicolumn{2}{|c|}{ Unclear } \\
\hline N & \multicolumn{2}{|l|}{14,527} & \multicolumn{2}{|l|}{8760} & \multicolumn{2}{|l|}{3048} & \multicolumn{2}{|l|}{2719} \\
\hline \multicolumn{9}{|l|}{ Age } \\
\hline Mean & \multicolumn{2}{|l|}{75.10} & \multicolumn{2}{|l|}{75.08} & \multicolumn{2}{|l|}{75.48} & \multicolumn{2}{|l|}{74.73} \\
\hline Standard Deviation & \multicolumn{2}{|l|}{9.35} & \multicolumn{2}{|l|}{9.34} & \multicolumn{2}{|l|}{9.35} & \multicolumn{2}{|l|}{9.37} \\
\hline Median & \multicolumn{2}{|l|}{76} & \multicolumn{2}{|l|}{76} & \multicolumn{2}{|l|}{77} & \multicolumn{2}{|l|}{76} \\
\hline \multicolumn{9}{|l|}{ Age group (n, \%) } \\
\hline 50 to $<60$ & 825 & $5.68 \%$ & 474 & $5.41 \%$ & 176 & $5.77 \%$ & 175 & $6.44 \%$ \\
\hline 60 to $<70$ & 3336 & $22.96 \%$ & 2084 & $23.79 \%$ & 629 & $20.64 \%$ & 623 & $22.91 \%$ \\
\hline 70 to $<80$ & 5094 & $35.07 \%$ & 3014 & $34.41 \%$ & 1082 & $35.50 \%$ & 998 & $36.70 \%$ \\
\hline 80 to $<90$ & 4659 & $32.07 \%$ & 2820 & $32.19 \%$ & 1021 & $33.50 \%$ & 818 & $30.08 \%$ \\
\hline$>=90$ & 613 & $4.22 \%$ & 368 & $4.20 \%$ & 140 & $4.59 \%$ & 105 & $3.86 \%$ \\
\hline \multicolumn{9}{|l|}{ Gender (n, \%) } \\
\hline Male & 2972 & $20.46 \%$ & 1801 & $20.56 \%$ & 651 & $21.36 \%$ & 520 & $19.12 \%$ \\
\hline Female & 11,555 & $79.54 \%$ & 6959 & $79.44 \%$ & 2397 & $78.64 \%$ & 2199 & $80.88 \%$ \\
\hline \multicolumn{9}{|l|}{ Hospital Category (n, \%) } \\
\hline General Hospital & 8816 & $60.69 \%$ & 5313 & $60.65 \%$ & 1654 & $54.27 \%$ & 1849 & $68.00 \%$ \\
\hline TCM Hospital & 4100 & $28.22 \%$ & 2868 & $32.74 \%$ & 534 & $17.52 \%$ & 698 & $25.67 \%$ \\
\hline Orthopaedic Hospital & 856 & $5.89 \%$ & 173 & $1.97 \%$ & 643 & $21.10 \%$ & 40 & $1.47 \%$ \\
\hline ITCWM Hospital & 703 & $4.84 \%$ & 362 & $4.13 \%$ & 216 & $7.09 \%$ & 125 & $4.60 \%$ \\
\hline MCC Hospital & 30 & $0.21 \%$ & 23 & $0.26 \%$ & 0 & $0.00 \%$ & 7 & $0.26 \%$ \\
\hline Other Hospitals & 22 & $0.15 \%$ & 21 & $0.24 \%$ & 1 & $0.03 \%$ & 0 & $0.00 \%$ \\
\hline \multicolumn{9}{|l|}{ Hospital Level (n, \%) } \\
\hline Tertiary & 13,388 & $92.16 \%$ & 8003 & $91.36 \%$ & 2728 & $89.50 \%$ & 2657 & $97.72 \%$ \\
\hline Secondary & 1081 & $7.44 \%$ & 724 & $8.26 \%$ & 314 & $10.30 \%$ & 43 & $1.58 \%$ \\
\hline Primary & 48 & $0.33 \%$ & 30 & $0.34 \%$ & 6 & $0.20 \%$ & 12 & $0.44 \%$ \\
\hline Unknown & 10 & $0.07 \%$ & 3 & $0.03 \%$ & 0 & $0.00 \%$ & 7 & $0.26 \%$ \\
\hline \multicolumn{9}{|l|}{ Admission Year (n, \%) } \\
\hline 2015 & 4105 & $28.26 \%$ & 1467 & $16.75 \%$ & 629 & $20.64 \%$ & 2009 & $73.89 \%$ \\
\hline 2016 & 5799 & $39.92 \%$ & 3926 & $44.82 \%$ & 1387 & $45.51 \%$ & 486 & $17.87 \%$ \\
\hline 2017 & 4623 & $31.82 \%$ & 3367 & $38.44 \%$ & 1032 & $33.86 \%$ & 224 & $8.24 \%$ \\
\hline
\end{tabular}

Abbreviation: TCM Traditional Chinese Medicine, ITCWM Integrated Traditional Chinese and Western Medicine, MCC Maternity and Child Care Note: Unclear means patient underwent PVP/PKP but could not distinguish the type of surgery

Among all the patients during the study period, the re-surgery rate was $1.22 \%$ in 30 days, $2.58 \%$ in 90 days, $3.61 \%$ in 183 days, $5.42 \%$ in 1 year, and $7.95 \%$ in 2 years (Table 4; Figs. 2 and 3). Median time interval to resurgery was 139 days (Table 5). There was no significant difference in the re-surgery rate between PVP and PKP, regardless of the type of statistical tests (Log-rank: $p=$ 0.3897; Wilcoxon: $p=0.1829$ ).

\section{Direct medical costs}

The annual total costs attributable to PVP/PKP related hospitalisation from 2015 to 2017 were 153 million CNY

Table 2 PVP/PKP surgery rate for patient diagnosed as OVCF

\begin{tabular}{llll}
\hline & Total & PVP & PKP \\
\hline The number of vertebral fracture patient* & 50,686 & - & - \\
The number of PVP/PKP patient & 14,527 & 8767 & 3057 \\
The proportion of PVP/PKP among those having vertebral fracture & $28.66 \%$ & $17.30 \%$ & $6.03 \%$ \\
\hline
\end{tabular}

Note: *All vertebral fractures patients who meet inclusion/exclusion criteria are considered as OVCF 
Table 3 Length of stay for patient receiving PVP/PKP (day)

\begin{tabular}{lllll}
\hline & Total Population & PVP & PKP & Unclear \\
\hline $\mathrm{N}$ & 15,599 & 3277 & 9477 & 2845 \\
Mean & 10.66 & 11.74 & 10.43 & 10.15 \\
Standard Deviation & 8.06 & 8.54 & 8.25 & 6.63 \\
Minimum & 1 & 1 & 1 & 1 \\
1st Quartile & 6 & 7 & 6 & 6 \\
Median & 9 & 10 & 9 & 9 \\
3rd Quartile & 13 & 14 & 13 & 12 \\
Maximum & 256 & 191 & 256 & 92 \\
\hline
\end{tabular}

(22 million USD), 178 million CNY (25 million USD), and 229 million CNY (33 million USD), respectively. The overall costs of hospitalisation were 187 million CNY (27 million USD) per year in this anonymised metropolitan city of China (Table 6).

Total costs per PVP/PKP hospitalisation averaged 35, 906 CNY (5122 USD) (Table 7). The total costs of PKP hospitalisation were significantly higher than that of PKP [34,195 CNY (4878 USD) for PVP, 44,414 CNY (6336 USD) for PKP, $P<0.01$ ] (Table 8 ).

\section{Subgroup analyses}

Median LOS was 9 days for both male and female. However, the statistical test showed that the difference in LOS distribution between male and female was significant $(p<0.01)$. Median LOS was $8,8,9,10,10$ for each age groups, respectively. The difference among age groups was also statistically significant $(\mathrm{p}<0.01)$. (Supplementary Table 1).

The 2-year cumulative re-surgery rates were $6.92 \%$ for male and $8.20 \%$ for female, respectively. Patients in the 50-59 age group had the lowest 2-year cumulative re- surgery rate $(4.48 \%)$, while patients in $80-89$ age groups had the highest $(10.22 \%)$. The statistical difference was not significant $(p=0.192)$ between sex but significant among age groups $(p<0.01)$. (Supplementary Table 2$)$.

The average hospital costs of the male were significantly higher than that of female $[37,950 \mathrm{CNY}$ (5414USD) vs $35,383 \mathrm{CNY}$ (5048USD), $\mathrm{p}<0.01]$. There were also significant differences in the average costs of hospitalisation for different age groups $(\mathrm{p}<0.01)$, with patients in 50-59 age group having the highest costs [37,970CNY (5417USD)] and patients in 60-69 age group having the lowest [35,221CNY (5024USD)]. (Supplementary Table 3 and 4).

\section{Sensitivity analysis}

Patients with exact OVCF diagnosis were included in the sensitivity analysis. 18,567 OVCF patients with 23, 056 visits were identified, among them 6237 (33.59\%) patients received PVP/PKP with 6538 records (Supplementary Table 5). Of these patients undergoing surgery, $1086(17.41 \%)$ were male and $5151(82.59 \%)$ were female; they were 75 -year-old on average.

Median LOS in hospitals was 9 days, of which PVP was 8 days and PKP was 10 days (Supplementary Table 6). The re-surgery rate was $0.93 \%$ in 30 days, $2.10 \%$ in 90 days, $2.75 \%$ in 183 days, $3.63 \%$ in 1 year, and $5.51 \%$ in 2 years Supplementary Table 7 ). There was no difference in re-surgery rate between the PVP and PKP (Supplementary Table 8). The median time interval to re-surgery was 97 days (Supplementary Table 9). Total costs per hospitalisation averaged 34,561 CNY (4930 USD) (Supplementary Table 10).

In addition, outliers of costs and time interval were jointly checked. In 14,527 patients, 28 patients had time

Table 4 Re-surgery rate for patient receiving PVP/PKP (by patient)

\begin{tabular}{|c|c|c|c|c|c|c|c|c|c|c|c|c|}
\hline \multirow[t]{2}{*}{ Time } & \multicolumn{3}{|c|}{ Total Population } & \multicolumn{3}{|l|}{ PVP } & \multicolumn{3}{|l|}{ PKP } & \multicolumn{3}{|l|}{ Unclear } \\
\hline & $\begin{array}{l}\text { Re-surgery } \\
\text { rate }\end{array}$ & SE & $95 \% \mathrm{Cl}$ & $\begin{array}{l}\text { Re-surgery } \\
\text { rate }\end{array}$ & SE & $95 \% \mathrm{Cl}$ & $\begin{array}{l}\text { Re-surgery } \\
\text { rate }\end{array}$ & SE & $95 \% \mathrm{Cl}$ & $\begin{array}{l}\text { Re-surgery } \\
\text { rate }\end{array}$ & SE & $95 \% \mathrm{Cl}$ \\
\hline 30 days & 0.0122 & 0.0009 & $\begin{array}{l}(0.0105, \\
0.0141)\end{array}$ & 0.0124 & 0.0012 & $\begin{array}{l}\text { (0.0103, } \\
0.0149)\end{array}$ & 0.0135 & 0.0021 & $\begin{array}{l}(0.0099, \\
0.0182)\end{array}$ & 0.0103 & 0.0019 & $\begin{array}{l}(0.0071, \\
0.0149)\end{array}$ \\
\hline 90 days & 0.0258 & 0.0013 & $\begin{array}{l}(0.0233, \\
0.0285)\end{array}$ & 0.0249 & 0.0017 & $\begin{array}{l}(0.0218, \\
0.0284)\end{array}$ & 0.0296 & 0.0031 & $\begin{array}{l}(0.0241 \\
0.0362)\end{array}$ & 0.0243 & 0.0030 & $\begin{array}{l}(0.0192, \\
0.0309)\end{array}$ \\
\hline $\begin{array}{l}183 \\
\text { days }\end{array}$ & 0.0361 & 0.0016 & $\begin{array}{l}(0.0332, \\
0.0393)\end{array}$ & 0.0352 & 0.0020 & $\begin{array}{l}(0.0315 \\
0.0393)\end{array}$ & 0.0397 & 0.0036 & $\begin{array}{l}(0.0333 \\
0.0473)\end{array}$ & 0.0352 & 0.0036 & $\begin{array}{l}(0.0289, \\
0.0429)\end{array}$ \\
\hline $\begin{array}{l}365 \\
\text { days }\end{array}$ & 0.0542 & 0.0020 & $\begin{array}{l}(0.0504, \\
0.0582)\end{array}$ & 0.0520 & 0.0025 & $\begin{array}{l}(0.0472 \\
0.0572)\end{array}$ & 0.0615 & 0.0046 & $\begin{array}{l}(0.0530, \\
0.0712)\end{array}$ & 0.0528 & 0.0043 & $\begin{array}{l}(0.0530, \\
0.0712)\end{array}$ \\
\hline $\begin{array}{l}730 \\
\text { days }\end{array}$ & 0.0795 & 0.0027 & $\begin{array}{l}(0.0743, \\
0.0850)\end{array}$ & 0.0796 & 0.0038 & $\begin{array}{l}(0.0723 \\
0.0875)\end{array}$ & 0.0833 & 0.0064 & $\begin{array}{l}(0.0716, \\
0.0968)\end{array}$ & 0.0770 & 0.0053 & $\begin{array}{l}(0.0672 \\
0.0881)\end{array}$ \\
\hline $\begin{array}{l}1090 \\
\text { days }\end{array}$ & 0.0896 & 0.0033 & $\begin{array}{l}(0.0834, \\
0.0963)\end{array}$ & 0.0946 & 0.0051 & $\begin{array}{l}(0.0851 \\
0.1051)\end{array}$ & 0.0945 & 0.0077 & $\begin{array}{l}(0.0805, \\
0.1109)\end{array}$ & 0.0798 & 0.0056 & $\begin{array}{l}(0.0695, \\
0.0916)\end{array}$ \\
\hline
\end{tabular}

Abbreviation: SE Standard Error, Cl Confidence Interval 


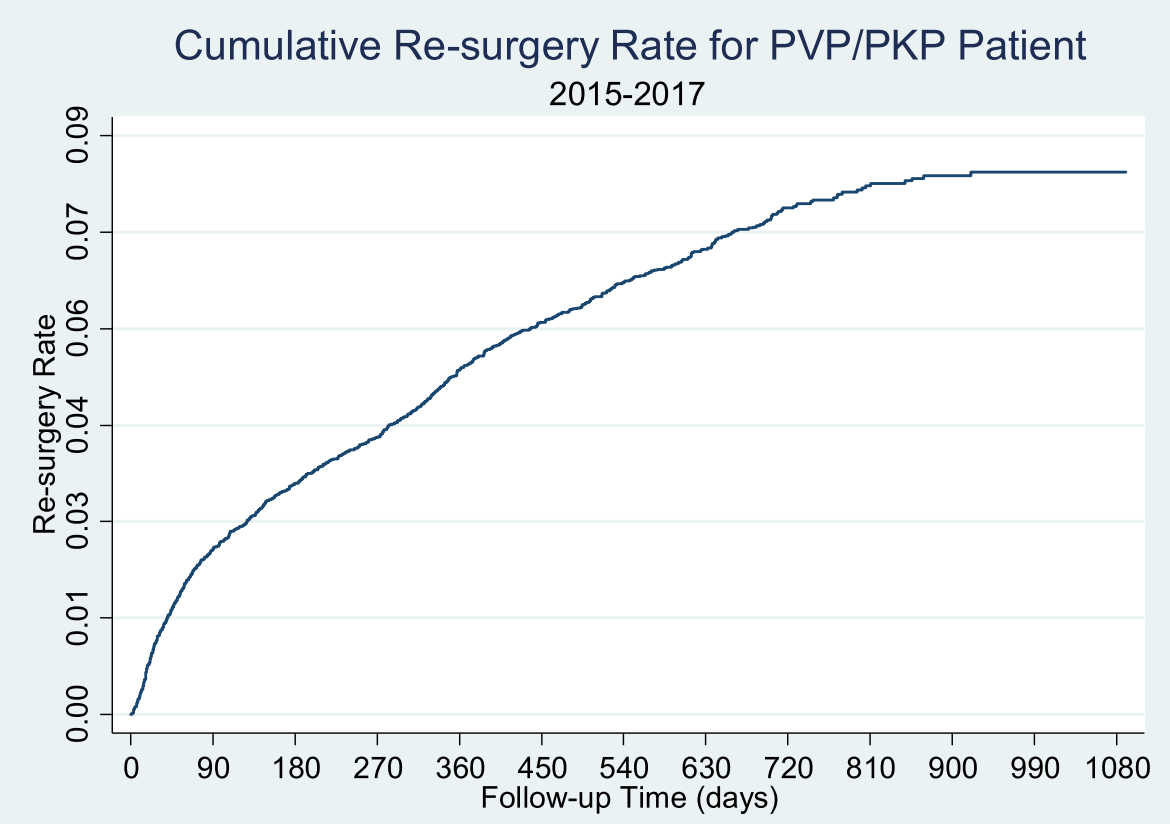

Fig. 2 Re-surgery Rate for PVP/PKP Patient, by Kaplan-Meier Curve

interval to re-surgery less than 7 days; only 2 of them had total costs less than $13,842 \mathrm{CNY} / 1975 \mathrm{USD}$ (the 5 th percentile of total costs distribution); 13 of them had total costs less than 33,416CNY/4767USD (the median of total costs). Re-surgery and first surgery of these patients can be considered as one treatment. However, due to the very small patient number, it does not affect the overall results.

\section{Discussion}

This study was a retrospective longitudinal study aiming at measuring the burden of PVP/PKP due to OVCF in

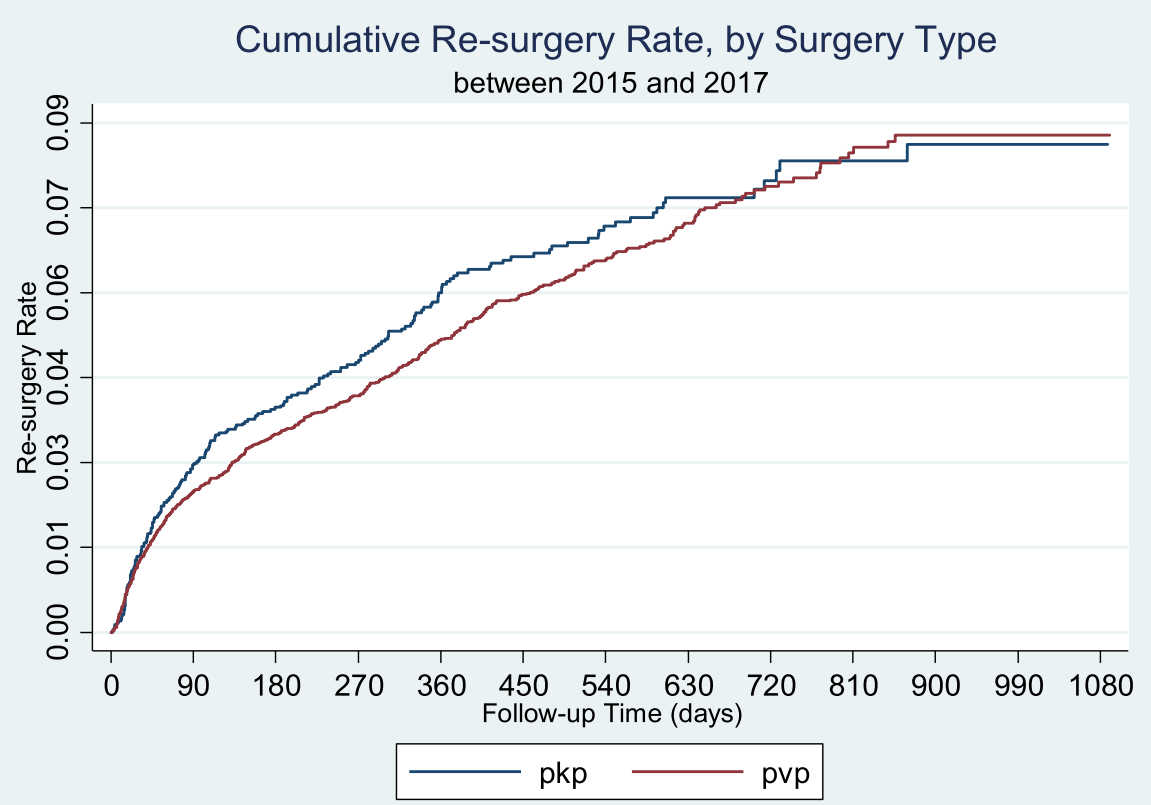

Fig. 3 Re-surgery Rate for PVP/PKP Patient respectively, by Kaplan-Meier Curve 
Table 5 Time interval to re-surgery for patient receiving more than once PVP/PKP

\begin{tabular}{lllll}
\hline & Total Population & PVP & PKP & Unclear \\
\hline $\mathrm{N}$ & 916 & 516 & 200 & 200 \\
Mean & 211.383 & 202.7035 & 181.54 & 263.62 \\
Standard Deviation & 203.591 & 200.0735 & 181.4055 & 224.165 \\
Minimum & 0 & 0 & 0 & 2 \\
1st Quartile & 43 & 38 & 39 & 59 \\
Median & 139 & 131 & 107 & 194 \\
3rd Quartile & 338 & 328 & 294 & 428 \\
Maximum & 920 & 856 & 869 & 920 \\
\hline
\end{tabular}

China from the payer perspective. To our knowledge, our study was the first to estimate the utilisation of PVP/PKP procedures and their costs for OVCF treatment in China by analysing real-world city-wide claims data. We noted the utilisation of PVP/PKP was high for OVCF patients with $28.66 \%$ PVP/PKP surgery rate and $7.95 \%$ 2-year cumulative re-surgery rate. Median LOS in hospitals was 9 days, and median time interval to resurgery was 139 days. Hospitalisation costs due to PVP/ PKP were high: per hospitalisation cost averaged 35,906 CNY (5122 USD), and annual hospitalisation costs in the metropolitan city totalled 187 million CNY (27 million USD). It brought a significant burden to both medical insurance institution and patients.

Subgroup analyses and sensitivity analysis indicated that men had shorter hospital stays but higher hospital costs than women. In addition, there was no difference in reoperation rates between men and women. With the increase of age, both LOS and the re-surgery rates increased (the sudden drop in the resurgery rate in $90+$ age group might be due to the impact of sample size, mortality, etc.). However, the costs of hospitalisation for the 50-59 age group were the highest, which emphasized the value of early intervention for osteoporosis.

Overall, the results of this study were comparable with those of previous studies. In this study, the number of female OVCF patients was about 2.3 times that of male patients, which is consistent with the higher risk of OVCF in females in other studies $[1,4,8,22]$. The surgery rate of PVP/PKP in OVCF patients in our study was also similar to the finding of another study at $23.1 \%$ [23]. A comparison of re-surgery rate among studies was

Table 6 Annual costs for PVP/PKP patients (CNY)

\begin{tabular}{lllll}
\hline & 2015 & 2016 & 2017 & Mean \\
\hline Annual costs & $152,759,120$ & $178,167,264$ & $228,915,056$ & $186,613,813$ \\
Annual visits & 4250 & 5109 & 6240 & - \\
\hline
\end{tabular}

not conducted due to the lack of studies on PVP/PKP re-surgery rates.

Whether it is PVP or PKP, surgery-related inpatient costs are high. In contrast, taking a short-term view, PVP seems to be better than PKP because there was no significant difference in the re-surgery rate between PVP and PKP, but the costs of PVP were nearly $30 \%$ lower than that of PKP. Another clinical study in China also recommended PVP because the clinical result (pain relief) differed little but the costs of PKP were higher [24]. However, due to the lack of confounder control in this study, we should be more cautious about asserting a causal relationship between surgery types and the outcomes. The costs associated with vertebral fractures in many countries are well documented: in America, the costs per surgery-related hospitalisation were 7805 USD (54,713 CNY) for PVP and 12,032 USD (84,344 CNY) for PKP in 2006, 9837 USD $(68,957$ CNY) for PVP and 13,187 USD (92,441 CNY) for PKP in 2007 and 2008 $[25,26]$. The results of US studies are similar to our study, where the costs of PKP hospitalisation were higher than PVP. However, it is worth noting that in terms of long-term costs, the results are reversed. In America, the two-year cumulative costs were 44,496 USD $(311,917$ CNY) for PVP and 41,339 USD $(289,786$ CNY) for PKP between 2006 and 2010 [27]. In Germany, patients' four-year cumulative costs were 42,510 EUR (330,775 CNY/47,186USD) for PVP and 39,014 EUR (303,529 CNY/43,306USD) for PKP between 2006 and 2010 [28]. One reason is that patients with PKP surgery use fewer drugs and pay lower maintenance costs after surgery. PKP significantly reduced $6.8-7.9 \%$ treatment costs during the 2-year post-surgery periods in America and reduced $33 \%$ painkiller costs during the 4-year postsurgery periods in German [27, 28]. The surgical sequelae and its burden would be an interesting point for future research.

Aside from surgery intervention, conservative treatment for OVCF is widely employed in China. Conservative treatment is recommended for mild/chronic OVCF, while severe/acute OVCF is treated by surgery [29]. Anticoagulant therapy of low molecular weight heparin calcium injection can be given during bed rest; nonsteroidal anti-inflammatory analgesics are mainly used to relieve acute pain; anti-osteoporosis medication, such as alendronate sodium, and complex calcium carbonate vitamin $\mathrm{D}$ tablets can also be employed [29, 30]. In terms of treatment effect, for pain relief, the short-term effect of surgery is better than that of conservative treatment, but no difference was observed in terms of longterm effect [31-35]. Recently, a study indicated that conservative treatment with anabolic drug could achieve comparative outcomes than PVP/PKP in treating acute OVCF [36]. However, from the perspective of recovery 
Table 7 The distribution of costs for PVP/PKP patients per hospitalisation (CNY)

\begin{tabular}{|c|c|c|c|c|c|c|c|c|}
\hline Costs Classification & $\mathrm{N}$ & Mean & S.D & Minimum & 1st Quartile & Median & 3rd Quartile & Maximum \\
\hline \multicolumn{9}{|l|}{ Comprehensive Medical Services } \\
\hline General Medical Service & 14,333 & 561 & 712 & 0 & 276 & 427 & 654 & 24,743 \\
\hline General Treatment Operation & 14,332 & 325 & 1072 & 0 & 71 & 136 & 266 & 47,826 \\
\hline Nursing & 14,775 & 184 & 285 & 0 & 72 & 118 & 209 & 11,840 \\
\hline \multicolumn{9}{|l|}{ Diagnosis } \\
\hline Laboratory Diagnosis & 14,631 & 1221 & 1097 & 0 & 732 & 1007 & 1360 & 44,375 \\
\hline Imaging Diagnosis & 14,456 & 2083 & 1191 & 0 & 1268 & 1938 & 2641 & 13,672 \\
\hline Clinical Diagnosis & 14,332 & 157 & 520 & 0 & 26 & 45 & 133 & 22,454 \\
\hline \multicolumn{9}{|l|}{ Treatment } \\
\hline Non-operative Treatment & 14,456 & 548 & 2421 & 0 & 0 & 60 & 332 & 78,637 \\
\hline Operative Treatment & 15,235 & 2721 & 2230 & 0 & 1825 & 1920 & 2755 & 72,731 \\
\hline Anesthetic Fee ${ }^{a}$ & 15,234 & 308 & 693 & 0 & 25 & 55 & 143 & 7953 \\
\hline Surgery Fee ${ }^{a}$ & 15,282 & 2234 & 1164 & 0 & 1800 & 1800 & 2340 & 28,000 \\
\hline \multicolumn{9}{|l|}{ Medicine } \\
\hline Western Medicine Fee & 15,597 & 3883 & 4673 & 0 & 1434 & 2848 & 4939 & 180,000 \\
\hline Antibiotics Fee ${ }^{a}$ & 14,332 & 211 & 1497 & 0 & 0 & 0 & 21 & 104,000 \\
\hline Chinese Patent Medicine Fee & 15,266 & 512 & 941 & 0 & 0 & 123 & 630 & 19,004 \\
\hline Chinese Herbal Medicine Fee & 15,091 & 70 & 179 & 0 & 0 & 0 & 51 & 5693 \\
\hline \multicolumn{9}{|l|}{ Materials } \\
\hline Disposable Medical Materials for Surgery & NA & 22,980 & NA & NA & NA & NA & NA & NA \\
\hline Disposable Medical Materials for Treatment & 14,864 & 1320 & 4891 & 0 & 20 & 118 & 380 & 82,753 \\
\hline Total Costs & 15,592 & 35,906 & 19,601 & 1000 & 24,042 & 33,416 & 42,079 & 365,000 \\
\hline Out-of-pocket Costs ${ }^{\mathrm{a}}$ & 14,652 & 17,752 & 16,885 & 0 & 5944 & 13,533 & 25,674 & 213,000 \\
\hline
\end{tabular}

Abbreviation: S. D Standard Deviation

Note: ${ }^{a}$ indicates secondary subject costs; Cost of Disposable Medical Materials for Surgery category: PVP data gained from chart review; PKP and Total data of this category inferred from the $64 \%{ }^{*}$ Total Cost

of vertebral stability and vertebral height, surgery is superior to conservative treatment [34].

Although successful PVP/PKP treatment for OVCF can effectively alleviate pains and other symptoms, the procedures are not free of untoward effects. Studies have explored that the PVP/PKP may accelerate local bone absorption due to bone cement, thereby increasing the risk of recurrent fracture of the surgical vertebra [3740]. In addition, studies also reported that additional stress of adjacent vertebrae caused by the cement augmentation and cement leakage are important factors in causing new adjacent vertebral fractures after PVP/PKP [41-44].

To avoid OVCF, anti-osteoporosis therapy should be considered as primary prevention. Osteoporosis and resulting osteoporotic vertebral fractures typically develop silently with a long-time window from the initial decrease in bone density to the occurrence of OVCF. Use of anti-osteoporosis drugs can reduce the risk of fractures. For women with osteoporosis but without vertebral fractures, alendronate significantly reduced the first vertebral fracture by $44 \%$ [45]. Studies have shown that anti-osteoporosis treatment after fracture can reduce the risk of re-fracture by $40 \%$ within 3 years [46]. In this regard, anti-osteoporosis treatment should be considered as part of long-term treatment strategies to reduce the risk of fracture [47-50]. Although antiosteoporosis therapy plays a significant role in OVCF prevention, the current situation of drug use is not optimistic. This might be due to the low diagnosis rate of osteoporosis and vertebral fractures. What's more, there is a large gap in the diagnosis and prevention of osteoporosis and vertebral fractures among different level hospitals, especially in community hospitals where the diagnosis ability is poor. Although inadequate diagnosis and prevention of osteoporosis is consensus, related real-world studies are lacking. The insufficiency of osteoporosis diagnosis and prevention can only be indirectly understood from the situation of fracture patients. A study in mainland China showed only $13.9 \%$ of patients used anti-osteoporosis drugs before fractures [23]. Moreover, a retrospective study showed that in China, the rate of misdiagnosis of vertebral fractures was 54.27\%; while in the patients with vertebral fractures 
Table 8 Average costs for PVP/PKP patients per hospitalisation (CNY), by surgery group

\begin{tabular}{|c|c|c|c|c|c|}
\hline \multirow[t]{2}{*}{ Costs Classification } & \multicolumn{2}{|l|}{ PVP } & \multicolumn{2}{|l|}{ PKP } & \multirow{2}{*}{$\begin{array}{l}\boldsymbol{P} \\
\text { value }\end{array}$} \\
\hline & Mean & S.D & Mean & S.D & \\
\hline \multicolumn{6}{|l|}{ Comprehensive Medical Services } \\
\hline General Medical Service & 548 & 696 & 602 & 690 & $<0.01$ \\
\hline General Treatment Operation & 350 & 1266 & 262 & 620 & $<0.01$ \\
\hline Nursing & 189 & 319 & 187 & 226 & $<0.01$ \\
\hline \multicolumn{6}{|l|}{ Diagnosis } \\
\hline Laboratory Diagnosis & 1245 & 1123 & 1164 & 1129 & $<0.01$ \\
\hline Imaging Diagnosis & 2054 & 1201 & 2224 & 1146 & $<0.01$ \\
\hline Clinical Diagnosis & 167 & 553 & 141 & 461 & $<0.01$ \\
\hline \multicolumn{6}{|l|}{ Treatment } \\
\hline Non-operative Treatment & 433 & 2010 & 633 & 1593 & $<0.01$ \\
\hline Operative Treatment & 2783 & 2578 & 2823 & 1596 & $<0.01$ \\
\hline Anesthetic Fee ${ }^{a}$ & 232 & 577 & 580 & 927 & $<0.01$ \\
\hline Surgery Fee ${ }^{a}$ & 2281 & 1278 & 2184 & 979 & $<0.01$ \\
\hline \multicolumn{6}{|l|}{ Medicine } \\
\hline Western Medicine Fee & 3737 & 4648 & 4383 & 5250 & $<0.01$ \\
\hline Antibiotics Fee ${ }^{a}$ & 197 & 1461 & 274 & 1918 & $<0.01$ \\
\hline Chinese Patent Medicine Fee & 513 & 980 & 510 & 906 & 0.69 \\
\hline Chinese Herbal Medicine Fee & 67 & 178 & 82 & 182 & 0.04 \\
\hline \multicolumn{6}{|l|}{ Materials } \\
\hline Disposable Medical Materials for Surgery & 21,885 & NA & 28,425 & NA & NA \\
\hline Disposable Medical Materials for Treatment & 1424 & 4904 & 1686 & 6108 & 0.03 \\
\hline Total Costs & 34,195 & 20,115 & 44,414 & 17,287 & $<0.01$ \\
\hline Out-of-pocket Costs ${ }^{\mathrm{a}}$ & 16,183 & 16,102 & 19,187 & 18,526 & $<0.01$ \\
\hline
\end{tabular}

Abbreviation: S. D Standard Deviation

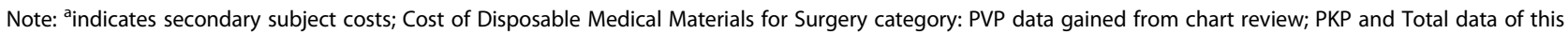
category inferred from the $64 \%{ }^{*}$ Total Cost; the method used for difference between groups is Mann-Whitney Test

diagnosis, $61.33 \%$ were definitely diagnosed as osteoporosis or OVCF, and only $28 \%$ were given antiosteoporosis therapy [51]. Compounding the problem is poor compliance with the medications as short-term medication intake has no evidentiary clinical benefits for fracture prevention [52-54]. In China, an analysis of medical insurance claims database from 2009 to 2010 showed that the adherence to bisphosphonate treatment was even worse with the mean Medication Possession Ratio (MPR) being 0.34, 0.22, and 0.15 at the 3rd, 6th, and 12th month over the follow-up period, respectively; moreover, only $2.1 \%$ patients were observed with high adherence (MPR > 0.8) during the 12-month follow-up [55].

The strength of our study stems from a welldefined study population which was population-based, i.e. residents of the metropolitan city covered by government health insurance were all included. The findings are likely to be more robust than those derived from a single hospital or hospitals from convenient sampling. Nevertheless, our study also has a number of limitations. On the one hand, some of the shortcomings of this study are due to the limitations of the database. Mortality and comorbidity are important in health research. However, our study was based on administrative claim database which was unable to support research about survival of patients in real world. Besides, claim database lacks detailed medical information in terms of comorbidity. In addition, researchers should be cautious about extrapolating findings to other regions or cities in China or to patients without health insurance because of variation in adopting surgical intervention for OVCF, health insurance coverage schemes and steep costs for self-paying patients. On the other hand, study design can lead to some estimation bias. First, we assumed all vertebral fracture cases meeting eligibility criteria were osteoporotic. This may include a few patients with non- 
osteoporotic vertebral fractures. In order to justify the assumption, we ran the sensitivity analysis among patients who had established OVCF diagnosis. The results were in line with those in the main analysis, which proves that our assumption is reliable. Second, there may be omissions in selecting PVP/PKP patients due to the lack of standardized procedure name, which would lead to the under-estimation of the surgery rate. Third, re-surgery rate calculation could also be underestimated due to the lack of knowledge of patients' history before 2015. In addition, because we only captured the records of hospitalisations during which surgery was performed, there are two circumstances of postoperative patient care: discharged at the same visit until full recovery; discharged shortly after surgery, home or transferred to other hospitals for postoperative care. In the latter case, since we were not able to make the linkage between surgery and rehabilitative stay, the LOS and costs of hospitalisation may be underestimated.

\section{Conclusion}

From 2015 to 2017, about a third of OVCF patients received PVP/PKP surgery and the 2-year cumulative resurgery rate reached $7.95 \%$. PVP/PKP due to OVCF brought a high economic burden on China's healthcare system. Early detection and treatment of patients with osteoporosis to prevent OVCF are critical in China.

\section{Appendix A: Keyword used in patient selection} Keywords used in inclusion criteria (Chinese)

Vertebral fracture diagnosis: “骨折” and “椎”

OVCF diagnosis: (“骨质疏松” or “骨松”) and (“骨折” and “椎”).

PVP/PKP: including ("PVP" or "PKP" or "pvp" or “pkp”) or (“经皮” and”椎体”) or 3(“椎”and”成形”and”成 型”) and excluding [“活检” or “椎板” or (“动脉” and “成 形”) or (“血管” and “成形”) or (“动脉” and “成型”) or (“血管” and “成型”) or “减压成形术” or “椎管” or “支 架” or “摘除术” or “消融” or “内固定” or “复位术” or “侧弯成形” or “封闭术” or “扩大成形” or “纤维环成形” or “髓核成形” or “臭氧成形” or “单开门成形”].

\section{Keywords used in exclusion criteria}

Tumour: “瘤”

Cancer hospital: “肿瘤医院”.

Spinal deformity and scoliosis: “脊柱” and (“畸形” or “侧弯” or “侧凸” or”后凸”).

Spondylitis: “脊柱炎”.

Disc herniation: “椎间盘” and (“突出” or “脱出”)

\section{Supplementary information}

Supplementary information accompanies this paper at https://doi.org/10 1186/s12891-020-03279-1.

\section{Additional file 1}

\section{Abbreviations}

OVCF: Osteoporotic vertebral compression fractures; PVP: Percutaneous vertebroplasty; PKP: Percutaneous kyphoplasty; LOS: Length of stay

\section{Acknowledgements}

We want to thank gratefully to Dr. Xiaohan Hu for his contribution to the revision and language polishing through the whole manuscript.

\section{Authors' contributions}

DHY has made contributions to the conception of the work; YLZ, XM, and $\mathrm{LH}$ have made contributions to the design of the work, the analysis and the interpretation of data, and the critical revision of the manuscript; LRL has made contributions to the design of the work, the analysis and the interpretation of data, the drafting and the critical revision of the manuscript; YG has made contributions to the design of the work, the acquisition of data, the interpretation of data, and the critical revision of the manuscript.

The authors read and approved the final manuscript.

\section{Funding}

Grants come from Eli Lilly and Company. Eli Lilly and Company participated in research design and manuscript revision.

Availability of data and materials

The datasets generated during and/or analysed during the current study are not publicly available due to government policy but are available from the corresponding author on reasonable request.

Ethics approval and consent to participate

Not applicable.

\section{Consent for publication}

Not applicable.

\section{Competing interests}

DHY declares that he has no competing interests; YLZ, XM, and LH declares that they are Eli Lilly and Company's employees; LRL and YG report grants from Eli Lilly and Company, during the conduct of the study.

\section{Author details}

'Department of Spinal Surgery, Nanfang Hospital, Southern Medical University, AD: No.1838 North Guangzhou Avenue, Guangzhou 510515, PR China. ${ }^{2}$ Shanghai Branch, Lilly Suzhou Pharmaceutical Co.Ltd, AD: No. 288 Shimen No.1 Road, Jing'an District, Shanghai 200041, PR China. ${ }^{3}$ Department of Health Economics, Shanghai Centennial Co. Ltd, AD: 702A, B Block, Fenglin International Center, No. 388 Fenglin Road, Shanghai 200030, PR China.

Received: 5 September 2019 Accepted: 7 April 2020

Published online: 17 April 2020

\section{References}

1. Yi P, Ma Y, Ma X, Chen B, Hong Y, Liu B, et al. The clinical guideline for osteoporotic compression fractures. Chinese J Osteoporos. 2015;21(06):64384.

2. Vijayakumar R, Büsselberg D. Osteoporosis: an under-recognized public health problem. J Local Glob Heal Sci. 2016;2016(1):2 [cited 2019 May 6]. Available from: http://www.qscience.com/doi/10.5339/jlghs.2016.2.

3. Wang Y, Tao Y, Hyman ME, Li J, Chen Y. Osteoporosis in China. Osteoporos Int. 2009;20(10):1651-62[cited 2019 May 6]. Available from:. https://doi.org/ 10.1007/s00198-009-0925-y.

4. Chen P, Li Z, Hu Y. Prevalence of osteoporosis in China: a meta-analysis and systematic review. BMC Public Health. 2016;16(1):1039 [cited 2019 May 6]. Available from: http://www.ncbi.nlm.nih.gov/pubmed/27716144.

5. Han Y, Tie X, Yilihamu T. Meta-analysis on the prevalence rate of osteoporosis in the middle-aged and elderly in China. Chinese J Tissue Eng Res. 2014;18(7):1129-34. 
6. Luo L, Sun X, Pi P, Ying K. The prevalence of osteoporosis in Chinese middle-aged and elderly population in recent 10 years: a mete-analysis. Chinese J Osteoporos. 2018;24(11):1415-19.

7. Choi SH, Kim D-Y, Koo JW, Lee SG, Jeong S-Y, Kang C-N. Incidence and management trends of osteoporotic vertebral compression fractures in South Korea: a nationwide population-based study. Asian Spine J. 2019; 14(2):220-8

8. Tang W, Hong W, Chen M, Du Y, Li H, Zheng S, et al. Investigation the prevalence and risk factors of vertebral fracture in community-dwelling elderly in Shanghai. Chinese J Endocrinol Metab. 2018:34(6):498-504.

9. Burge R, Dawson-Hughes B, Solomon DH, Wong JB, King A, Tosteson A. Incidence and economic burden of osteoporosis-related fractures in the United States, 2005-2025. J Bone Miner Res. 2007;22(3):465-75.

10. Lange A, Zeidler J, Braun S. One-year disease-related health care costs of incident vertebral fractures in osteoporotic patients. Osteoporos Int. 2014; 25(10):2435-43.

11. Hopkins RB, Burke N, Von Keyserlingk C, Leslie WD, Morin SN, Adachi JD, et al. The current economic burden of illness of osteoporosis in Canada. Osteoporos Int. 2016;27(10):3023-32.

12. Qu B, Ma Y, Yan M, Wu HH, Fan L, Liao DF, et al. The economic burden of fracture patients with osteoporosis in western China. Osteoporos Int. 2014 25(7):1853-60

13. Branch of Osteoporosis and Bone Mineral Salt Disease Chinese Medical Association. Guidelines for diagnosis and treatment of primary osteoporosis (2017). Chinese J Osteoporos Bone Miner Res. 2017;10(05):413-44.

14. Wang $\mathrm{O}$, Hu Y, Gong $\mathrm{S}$, Xue Q, Deng Z, Wang L, et al. A survey of outcomes and management of patients post fragility fractures in China. Osteoporos Int. 2015;26(11):2631-40[cited 2019 May 6]. Available from: https://doi.org/ 10.1007/s00198-015-3162-6.

15. Klazen CA, Lohle PN, de Vries J, Jansen FH, Tielbeek AV, Blonk MC, et al. Vertebroplasty versus conservative treatment in acute osteoporotic vertebral compression fractures (Vertos II): an open-label randomised trial. Lancet. 2010;376(9746):1085-92 [cited 2019 May 6]. Available from: https://www. sciencedirect.com/science/article/pii/S0140673610609543.

16. Zhao $S$, Xu C-Y, Zhu A-R, Ye L, Lv L-L, Chen L, et al. Comparison of the efficacy and safety of 3 treatments for patients with osteoporotic vertebral compression fractures: a network meta-analysis. Medicine (Baltimore). 2017; 96(26):e7328 [cited 2019 May 6]. Available from: http://www.ncbi.nlm.nih. gov/pubmed/28658144.

17. Zhang Y, Shi L, Tang P, Zhang L. Comparison of the efficacy between two micro-operative therapies of old patients with osteoporotic vertebral compression fracture: a network meta-analysis. J Cell Biochem. 2017;118(10): 3205-12[cited 2019 May 6]. Available from:. https://doi.org/10.1002/jcb. 25966.

18. Chen C, Li D, Wang Q, Xu X, Ma Y, Li Z, et al. The cost-effectiveness analysis of minimally invasive surgery and conservative treatment in elderly osteoporotic spinal fracture. China J Orthop Traumatol. 2016;29(7):614-8.

19. Luo J, Feng J, Zhang Z, Tan S, Guo X. Cost-effect analysis of conservative and minimally invasive method in the treatment of osteoporotic verbral compression fractures. J cervicodynia Lumbodynia. 2017;38(4):299-303.

20. Weizhong Y, Meng P, Guangwen Y. The cost-effectiveness of percutaneous kyphoplasty vs conservative treatment for elderly osteoporsis vertebral compression fracture. Chinese J Spine Spinal Cord. 2015;25(2):163-7 [cited 2019 Jul 24]. Available from: http://caod.oriprobe.com/articles/44493514/ The_cost_effectiveness_of_percutaneous_kyphoplasty_vs_conservative_tre. htm.

21. Wang $X$, Ji L, W Y, Y W, M F, Ouyang J. Comparison of clinical effect and costs between percutaneous vertebroplasty and kyphoplasty for the treatment of acute osteoporotic vertebral mild compression fractures. J Clin Orthop. 2012;15(2):125-8

22. Du Y, Tang W, Hong W, Al E. Current status of vertebral fracture in community-dwelling elderly in Shanghai and its difference between urban and suburban districts. Chinese J Osteoporos Bone Miner Res. 2017;10(04):367-74

23. Liu X. Risk and burden of subsequent fractures after first osteoporosisrelated fracture among osteoporosis patients: Tianjin University; 2016.

24. Liu JT, Liao WJ, Tan WC, Lee JK, Liu CH, Chen YH, et al. Balloon kyphoplasty versus vertebroplasty for treatment of osteoporotic vertebral compression fracture: a prospective, comparative, and randomized clinical study. Osteoporos Int. 2010;21(2):359-64 [cited 2019 Jun 28]Available from http:// link.springer.com/10.1007/s00198-009-0952-8.
25. Mehio AK, Lerner JH, Engelhart LM, Kozma CM, Slaton TL, Edwards NC, et al. Comparative hospital economics and patient presentation: vertebroplasty and kyphoplasty for the treatment of vertebral compression fracture. AJNR Am J Neuroradiol. 2011;32(7):1290-4 [cited 2019 Jul 24]. Available from: http://www.ncbi.nlm.nih.gov/pubmed/21546460.

26. Chen AT, Cohen DB, Skolasky RL. Impact of nonoperative treatment, Vertebroplasty, and Kyphoplasty on survival and morbidity after vertebral compression fracture in the Medicare population. J Bone Jt SurgeryAmerican Vol. 2013;95(19):1729-36 [cited 2019 Jun 28]. Available from: https://insights.ovid.com/crossref?an=00004623-201310020-00001.

27. Ong KL, Lau E, Kemner JE, Kurtz SM. Two-year cost comparison of vertebroplasty and kyphoplasty for the treatment of vertebral compression fractures: are initial surgical costs misleading? Osteoporos Int. 2013;24(4): 1437-45[cited 2019 Jun 28]. Available from:. https://doi.org/10.1007/s00198012-2100-0.

28. Lange A, Kasperk C, Alvares L, Sauermann S, Braun S. Survival and cost comparison of Kyphoplasty and percutaneous Vertebroplasty using German claims data. Spine (Phila Pa 1976). 2014;39(4):318-26 [cited 2019 May 6]. Available from: https://insights.ovid.com/crossref?an=00007632-20140215000016.

29. Zhengye J, Shengbao C, Changqing Z. Progress in research on osteoporotic vertebral compression fracture. Int J Orthop. 2018;39(1):33-6.

30. Yubao $H$, Longxi $R$, Jieyin $W$, Bo L. Multidisciplinary conservative treatment of osteoporotic vertebral compression fractures. J Med Res. 2018;47(8):1716.

31. Hongjun S, Xianghu P, Lei S. Comprehensive treatment of 64 cases of simple thoracolumbar vertebral compression fracture. J Pract Tradit Chinese Med. 2017;33(1):27-8.

32. Qichang S, Hanqing Z, Xiaohui W. Comparisons of percutaneous Kyphoplasty and conservative treatment on osteoporosis vertebra compression fracture: a meta analysis. J Jianghan Univ (Nat Sci Ed). 2018; 46(1):77-82.

33. Guojian C, Houcheng W, Weibo W. Comparison of percutaneous vertebroplasty and conservative treatment of osteoporotic vertebral compression fracture. China, Mod Med J. 2017;19(4):47-9.

34. Zhipeng W, Xiaogang Z, Yuanzhen L, Hongwei Z, Xiyun Z, Panju C, et al, Meta-analysis of percutaneous kyphoplasty and conservative treatment of osteoporotic vertebral compression fractures. Orthop J China. 2019;27(4): $336-41$.

35. Xiaohui W, Qingwu B, Lijian W, Guiren W. Comparing the efficacy of percutaneous vertebroplasty with conservative treatment for thoracolumbar vertebral compression fractures. J Mordern Med Heal. 2018;34(12):1816-9.

36. Glant TT, Jacobs JJ, Molnár G, Shanbhag AS, Valyon M, Galante JO. Bone resorption activity of particulate-stimulated macrophages. J Bone Miner Res. 1993:8(9):1071-9[cited 2019 Jul 26]. Available from:. https://doi.org/10.1002/ jbmr.5650080907.

37. Ma Y, Wu X, Xiao X, Ma Y, Feng $L$, Yan $W$, et al. Effects of teriparatide versus percutaneous vertebroplasty on pain relief, quality of life and costeffectiveness in postmenopausal females with acute osteoporotic vertebral compression fracture: a prospective cohort study. Bone. 2020;131:115154.

38. Eastell R, Barton I, Hannon R, Chines A, Garnero P, Delmas P. Relationship of early changes in bone resorption to the reduction in fracture risk with Risedronate. J Bone Miner Res. 2003;18(6):1051-6 [cited 2019 Jul 26]. Available from:. https://doi.org/10.1359/jbmr.2003.18.6.1051.

39. Meier C, Nguyen TV, Center JR, Seibel MJ, Eisman JA. Bone resorption and osteoporotic fractures in elderly men: the Dubbo osteoporosis epidemiology study. J Bone Miner Res. 2004;20(4):579-87 [cited 2019 Jul 26]. Available from: http://www.ncbi.nlm.nih.gov/pubmed/15765176.

40. Kim $Y-Y$, Park C-G, Rhyu K-W. Recompression of vertebral bodies after balloon Kyphoplasty for vertebral compression fractures - preliminary report. J Korean Soc Spine Surg. 2009;16(2):89 [cited 2019 Jul 26]. Available from: https://synapse.koreamed.org/DOlx.php?id=10.4184/jkss.2 009.16.2.89

41. Chen L-H, Hsieh M-K, Liao J-C, Lai P-L, Niu C-C, Fu T-S, et al. Repeated percutaneous vertebroplasty for refracture of cemented vertebrae. Arch Orthop Trauma Surg. 2011;131(7):927-33 [cited 2019 May 6]. Available from: http://link.springer.com/10.1007/s00402-010-1236-7.

42. Kim M-H, Lee AS, Min S-H, Yoon S-H. Risk factors of new compression fractures in adjacent vertebrae after percutaneous vertebroplasty. Asian Spine J. 2011;5(3):180-7 [cited 2019 Jul 26]. Available from: http://www.ncbi. nlm.nih.gov/pubmed/21892391. 
43. Tseng Y-Y, Yang T-C, Tu P-H, Lo Y-L, Yang S-T. Repeated and multiple new vertebral compression fractures after percutaneous Transpedicular Vertebroplasty. Spine (Phila Pa 1976). 2009;34(18):1917-22 [cited 2019 Jul 26]. Available from: https://insights.ovid.com/crossref?an $=00007632-2$ 00908150-00014.

44. Rho Y-J, Choe WJ, Chun Y II. Risk factors predicting the new symptomatic vertebral compression fractures after percutaneous vertebroplasty or kyphoplasty. Eur Spine J. 2012;21(5):905-11 [cited 2019 Jul 26]. Available from: http://link.springer.com/10.1007/s00586-011-2099-5.

45. Cummings SR, Black DM, Thompson DE, Applegate WB, Barrett-Connor E, Musliner TA, et al. Effect of alendronate on risk of fracture in women with low bone density but without vertebral fractures\&lt;SUBTITLE\&gt;results from the fracture intervention trial\&lt:/SUBTITLE\&gt. JAMA. 1998;280(24):2077 [cited 2019 Jul 26]. Available from: http://jama.jamanetwork.com/article. aspx?doi=10.1001/jama.280.24.2077.

46. Bawa HS, Weick J, Dirschl DR. Anti-osteoporotic therapy after fragility fracture lowers rate of subsequent fracture. J Bone Jt Surg. 2015;97(19): 1555-62 [cited 2019 Jul 26]. Available from: https:/insights.ovid.com/ crossref?an=00004623-201510070-00002.

47. Lin J, Shen X. Refracture analysis of 482 cases of osteoporosis fracture in hospitalized patients. Chinese J Geriatr Care. 2015;13(04):47-9.

48. Heo DH, Chin DK, Yoon YS, Kuh SU. Recollapse of previous vertebral compression fracture after percutaneous vertebroplasty. Osteoporos Int. 2009;20(3):473-80[cited 2019 May 6]. Available from:. https://doi.org/10. 1007/s00198-008-0682-3.

49. Zafeiris CP, Lyritis GP, Papaioannou NA, Gratsias PE, Galanos A, Chatziioannou SN, et al. Hypovitaminosis D as a risk factor of subsequent vertebral fractures after kyphoplasty. Spine J. 2012;12(4):304-12 [cited 2019 May 6]. Available from: https://www.sciencedirect.com/science/article/pii/ S1529943012001064

50. Moon E-S, Kim H-S, Park J-O, Moon S-H, Lee H-M, Shin D-E, et al. The incidence of new vertebral compression fractures in women after kyphoplasty and factors involved. Yonsei Med J. 2007;48(4):645-52 [cited 2019 May 6]. Available from: http://www.ncbi.nlm.nih.gov/ pubmed/17722237.

51. Du G, Yu W, Lin Q, Guan W. Underreporting of vertebral fractures on routine spinal computed tomography. Chinese J Osteoporos Bone Miner Res. 2017;10(4):350-5.

52. Siris ES, Harris ST, Rosen CJ, Barr CE, Arvesen JN, Abbott TA, et al. Adherence to bisphosphonate therapy and fracture rates in osteoporotic women: relationship to vertebral and nonvertebral fractures from 2 US claims databases. Mayo Clin Proc. 2006;81(8):1013-22 [cited 2019 May 6]. Available from: https://www.sciencedirect.com/science/article/abs/pii/S002561 9611612019.

53. Guyatt GH, Cranney A, Griffith L, Walter S, Krolicki N, Favus M, et al. Summary of meta-analyses of therapies for postmenopausal osteoporosis and the relationship between bone density and fractures. Endocrinol Metab Clin North Am. 2002;31(3):659-79 xii. [cited 2019 May 6]. Available from: http://www.ncbi.nlm.nih.gov/pubmed/12227126.

54. Huybrechts KF, Ishak KJ, Caro JJ. Assessment of compliance with osteoporosis treatment and its consequences in a managed care population. Bone. 2006;38(6):922-8 [cited 2019 May 6]. Available from: https://www.sciencedirect.com/science/article/pii/S8756328205004436.

55. Yu Q, Wu J. Analysis of the adherence and associated factors among osteoporosis patients. Chinese J Osteoporos. 2014;20(7):789.

\section{Publisher's Note}

Springer Nature remains neutral with regard to jurisdictional claims in published maps and institutional affiliations.

Ready to submit your research? Choose BMC and benefit from:
- fast, convenient online submission
- thorough peer review by experienced researchers in your field
- rapid publication on acceptance
- support for research data, including large and complex data types
- gold Open Access which fosters wider collaboration and increased citations
- maximum visibility for your research: over 100M website views per year
At BMC, research is always in progress.
Learn more biomedcentral.com/submissions

